\title{
The importance of the electrical properties of hydraulic fluids
}

\author{
Darko Lovrec and Vito Tič \\ Faculty of Mechanical Engineering, University of Maribor, Maribor, Slovenia
}

\begin{abstract}
Purpose - Apart from the basic material properties of liquid lubricants, such as, e.g., the viscosity and density of the hydraulic fluid, it is also important to have information regarding the electrical properties of the fluid used. The latter is closely related to the purpose, type, structure, and conditions of use of a hydraulic system, especially the powertrain design and fluid condition monitoring. The insulating capacity of the hydraulic fluid is important in cases where the electric motor of the pump is immersed in the fluid. In other cases, on the basis of changing the electrical conductive properties of the hydraulic fluid, we can refer its condition, and, on this basis, the degree of degradation.

Design/methodology/approach - The paper first highlights the importance of knowing the electrical properties of hydraulic fluids and then aims to compare these properties, such as the breakdown voltage of commonly used hydraulic mineral oils and newer ionic fluids suitable for use as hydraulic fluids.

Findings - Knowledge of this property is crucial for the design approach of modern hydraulic compact power packs. In the following, the emphasis is on the more advanced use of known electrical quantities, such as electrical conductivity and the dielectric constant of a liquid.

Originality/value - Based on the changes in these quantities, we have the possibility of real-time monitoring the hydraulic fluid condition, on the basis of which we judge the degree of fluid degradation and its suitability for further use.
\end{abstract}

Keywords Ionic liquids, Measurement, Dielectric constant, Breakdown voltage, Hydraulic fluids, Mineral based oils

Paper type Research paper

\section{Introduction}

Good knowledge of the physico-chemical properties of hydraulic fluid is a prerequisite for the correct, long-term, economically and environmentally sustainable use of the fluid built into a hydraulic system. Knowing the viscosity and density of the liquid, determining the presence of moisture, of solid particles and other contaminants, controlling the temperature of the liquid represent the basis. Less in use fluid acidity monitoring, FTIR analysis and wear particle analysis are used for more detailed condition analyses. These are more limited to laboratory tests. These tests somehow include knowledge of the characteristic electrical parameters of a fluid - its characteristic initial values and the course of their change. On the basis of known electrical values, we can decide on the design of the hydraulic unit, or on the basis of changing electrical values, we can conclude on the state of the installed fluid (Tič and Lovrec, 2017; Carey and Hayzen, 2001).

In some cases the hydraulic fluids are required to have similar properties as the transformer oils, such as insulating properties; in other cases the thermal and oxidation stability of the hydraulic fluid are in the forefront. Thermal and oxidation stability are two of the basic properties hydraulic oils must have, while the electric insulation is an additional requirement which must be met, for example, when the electric motor is submerged

The current issue and full text archive of this journal is available on Emerald Insight at: https://www.emerald.com/insight/0036-8792.htm

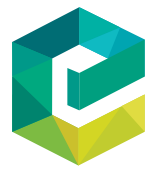

Industrial Lubrication and Tribology

74/3 (2022) 302-308

Emerald Publishing Limited [ISSN 0036-8792]

[DOI 10.1108/ILT-06-2021-0218] in the hydraulic fluid. In this case, the knowledge of the breakdown voltage of the fluid is very important.

On the other hand, knowing and monitoring the changes in the electrical values such as dielectric constant and electric conductivity of a hydraulic fluid provides a more detailed insight into the physical and chemical condition of the fluid, its degree of degradation and the prediction of the remaining service life (Meindorf, 2005).

Using appropriate on-line sensors, appropriate calibration and calibration of the fluid in question, knowledge of the mechanism of changes and influencing factors, monitoring changes in the dielectric constant, alone or in combination with tracking changes in other quantities, becomes a very advanced approach to online monitoring of hydraulic fluid, which offers many new options (Tič et al., 2014).

\footnotetext{
(C) Darko Lovrec and Vito Tič. Published by Emerald Publishing Limited. This article is published under the Creative Commons Attribution (CC BY 4.0) licence. Anyone may reproduce, distribute, translate and create derivative works of this article (for both commercial and non-commercial purposes), subject to full attribution to the original publication and authors. The full terms of this licence may be seen at http:/ creativecommons.org/licences/by/4.0/legalcode
}

The authors are grateful to the company OLMA d.o.o. from Ljubljana/ Slovenia, which allowed us to use their equipment and facilities, as well as the personnel to carry out very extensive experimental work. The authors also thank the company Proionic GmbH from Grambach/Austria, which provided all the samples of ionic liquids and was a very cooperative partner in the IL-selection process, for sharing their information with us. The authors are thankful to all colleagues in both companies who provided their expertise and skills that assisted this study greatly.

Received 18 June 2021

Revised 10 September 2021

Accepted 24 September 2021 


\section{Insulating properties and electric breakdown voltage}

The insulating capacity of a hydraulic fluid is crucial when designing the drive assembly of a hydraulic system - a hydraulic compact unit, where the drive electric motor, together with the pump, is often immersed in hydraulic fluid. Electric insulation is affected by:

- fluid humidity;

- particle content;

- gas content; and

- other contaminants. (Carey and Hayzen, 2001; Gunderson et al., 2011)

According to the international standard IEC 60296 (Edition 4, 2012 or Edition 5, 2020) "fluids for electro-technical applications - unused mineral insulation oils for electrical equipment", for transformers and switching the breakdown voltage of the transformer oil gives its resistance to electrical voltage in electrical equipment. (IEC 60296, 2020) The breakdown voltage is measured according to Standard IEC 60156 (IEC 60156, 2018). After special vacuum treatment for the reduction of particle, water and dissolved gas contents, the oil should have the dielectric strength and/or breakdown voltage of $>70 \mathrm{kV}$. Vacuum filtration of the oil is carried out at pressure $<25 \mathrm{kPa}$ and $60^{\circ} \mathrm{C}$ through sintered glass filters with the largest pore size $2.5 \mu \mathrm{m}$.

The breakdown voltage test according to method IEC 156 (present designation IEC 60156) is used to determine the electric breakdown voltage. In the standard test apparatus, the oil sample is exposed to an increasing alternating electric field with constant increasing of voltage up to breakdown between the two electrodes. The two electrodes may be made of brass, bronze or austenitic stainless steel. The axes must be horizontal and dipped at least $40 \mathrm{~mm}$ below the tested oil surface level. The distance between the two electrodes and the walls of the test cell of 350 to $600 \mathrm{ml}$ volume or the stirrer (optimal) must be at least $12 \mathrm{~mm}$. The distance between the two electrodes must be $2.5 \mathrm{~mm} \pm 0.05 \mathrm{~mm}$.

\subsection{Breakdown voltage - measurement and results}

The breakdown voltage test was performed according to the method IEC 156. Two ionic liquids IL-17PI045 and EMIM$\mathrm{EtSO}_{4}$, as new types of lubricant appropriate for use as a hydraulic fluid, were tested and values compared to the conventional HLP type mineral based hydraulic oil (Hydrolubric ${ }^{\circledR}$ VG 46, manufacturer OLMA), as well to the HFD-U type fire resistant hydraulic fluid (Quintolubric ${ }^{\circledR}$ 888-46, manufacturer Quaker). Measurements were performed by the use of the Megger OTS 60 PB apparatus.

Two measurements were carried out for each fluid sample in conformation with the standard. The results are indicated in Table 1.

The breakdown voltage of the Hydrolubric $($ VG 46 oil, the most used HLP type hydraulic mineral-based oil, is very good and is quite comparable to the best transformer oil before treatment (usually $40 \mathrm{kV}$ to $60 \mathrm{kV}$ ). After the usual vacuum filtration, based on our own experience, it would certainly exceed the $70 \mathrm{kV}$ required by the IEC 60156 standard. Quintolubric ${ }^{2} 888-4$, which was designed to replace antiwear, mineral oil-based hydraulic fluids used in applications
Table 1 Breakdown voltages of mineral hydraulic oil, HFD-U fluid and ionic liquids

\begin{tabular}{lc}
\hline Sample & $\begin{array}{c}\text { Breakdown voltage } \\
{[\mathrm{kV}]}\end{array}$ \\
\hline Hydrolubric VG 46 & 60 \\
Quintolubric 888-46 & 30 \\
EMIM-EtSO4 & $<1.0$ \\
IL-17PI045 & $<1.0$ \\
\hline
\end{tabular}

where fire hazards exist, has a suitable, but lower value of breakdown voltage. Qunitolubric ${ }^{\circledR} 888-46$ can also be used in environmentally sensitive hydraulic applications without compromising the overall hydraulic system operations. This fluid does not contain water, mineral oil or phosphate ester, and it is based on high-quality, synthetic, organic esters and carefully selected additives to achieve excellent hydraulic fluid performance.

On the other hand, the breakdown voltages of the tested ionic liquids are very low. Similar low breakdown voltage values apply to most other ionic liquids suitable for use as a hydraulic fluid. Therefore, they are unsuitable for applications where the electric motor would be submerged in oil. That aspect must be considered when constructing hydraulic systems with small, compact units where, in some configurations, the electric motor (without housing) is submerged directly in the hydraulic fluid. For usual hydraulic units that hydraulic liquid property is less important.

\subsection{Breakdown voltage and power pack design}

In conventional forms of hydraulic power units, wherein the drive assembly (electric motor-clutch-pump) is mounted on the tank cover, or is placed next to or under the tank, usually with a larger volume of hydraulic fluid, this material property of the fluid is not important or in the foreground of tank design.

However, this material property is extremely important for small, so-called compact power packs. In this case, the electric motor for the pump is installed beneath the fluid level inside the tank and is without the usual classical motor housing; a closed housing, or whose housing also performs the tank function. In addition to a very compact design, this type of design also has other advantages, such as the electric motor is cooled by the fluid and the noise from the motor is silenced. But, on other hand, there is some disadvantage: power is lost due to the shear stress of the fluid in the gap between the rotor and the stator of the electric motor and churning losses. An example of the appearance and interior design of such power packs is shown in Figure 1.

Hydraulic compact power packs require little space, even with attachments mounted. The housing of the power pack also serves as a hydraulic fluid tank. This accommodates the fluid-submerged motor and the feed pump in the form of a ruggedly built pump, which is constructed directly onto the motor shaft. This eliminates the need for a coupling, and the efficiency of the motor-pump combination is also improved. Furthermore, the larger cooling capacity of the hydraulic fluid as compared to air cooling makes it possible to use a motor with considerably lower-rated power and smaller dimensions than a standard air-cooled motor. This also reduces energy losses 
Figure 1 Interior tank design of compact hydraulic power packs
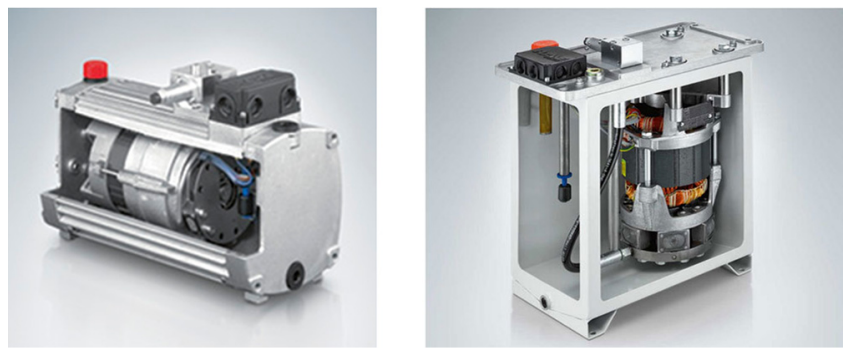

Source: HAWE, type KA, left and type MNP, right

when starting up. In addition, the fluid-submerged design allows the housing dimensions, tank volumes and oil requirement to be reduced to a minimum. The compact power packs are especially well suited for wind power plants. They provide a usable filling volume of two litres, which can be increased up to eleven litres with optional tank extensions. If the unit is used to supply several functions the larger type is recommended, because it has a usable filling volume of up to 25 litres. The compact power pack allows fluid to be supplied at a pressure of up to 700 bars.

A prerequisite for this design of the unit is that the hydraulic fluid has good insulating properties. According to the results of the breakdown voltage measurements, (the most commonly used) Ionic liquids are not suitable for such power pack design. In the case of the use of ionic liquids, which have many other advantages over conventional mineral oils, such as, e.g. extraordinary lubricating ability, are considered to be de-facto non-flammable, environmentally friendly, with a high value of the VI index ( $\gg 170)$ and, thus, an extremely wide temperature operating range, a very low flow point (up to $-60^{\circ} \mathrm{C}$ ), practically zero vapour pressure, it is necessary to adjust the power pack design accordingly.

\section{Dielectric constant and fluid condition monitoring}

Determining oil quality usually requires complex laboratory equipment to measure the viscosity, density, acid number (AN), water content, metals (additives and wear metals), colour and flash point. However, the dielectric constant is another important indicator of oil quality that is easy to measure on-site or on-line.

When the dielectric constant of lubricating oil is measured, changes in the dielectric constant of the used oil compared to new oil may indicate the presence of contaminants, such as water or particles, or changes in chemistry of the oil such as additive depletion or oxidation. It can also be one of the parameters on the basis of which it can be determinated the current condition of the fluid, most often hydraulic mineral oils. In the case that the dielectric constant is monitored continuously or at certain time intervals, the engineers can determine the trend of changes, current condition of the fluid and its suitability for the further use.

\subsection{Electric conductivity and dielectric constant}

The hydraulic fluid ageing and degradation is usually associated with changes in the chemical molecular structure, usually expressed as changes of the electric properties of the fluid (like its ability to polarize). Therefore, the electric conductivity $\sigma$ and dielectric constant, also called relative permittivity $\varepsilon_{\mathrm{r}}$, are two parameters able to illustrate quite well the changes of hydraulic fluid condition. The dielectric constant of the fluid is actually an indicator of its polarity. Base oils and additive packages with different chemistry and from different manufacturers may differ in their polarity. The polarity of the fluid is, thus, a feature through which oil confusion, oil mixtures and refreshments can be detected. Furthermore, oils change their polarity during the ageing process. Thus, it is also possible to monitor the course of ageing (Tič and Lovrec, 2017).

Fresh mineral oils have their characteristics, dielectric constant and electric conductivity, usually at low values. As the two parameters are specific fluid properties, they allow for detection:

- oil change: ingress of other oil types, or oil of another producer can be detected (different additive packages;

- ageing mechanisms: due to the oil ageing processes (oxidation and additive decomposition) acid products are formed in the oil, changing the base oil conductivity; dielectric constant and electric conductivity monitoring allows for observation of the oil ageing trends and formulating conclusions about its degradation;

- oil refreshing: with the value decrease, the fluid or filling refreshing is detected; and

- oil contamination: contaminants frequently met in hydraulic oils have much higher dielectric constant and electric conductivity than the hydraulic oil, as shown in Table 2. Therefore, any slight increase in concentration of a certain contaminant could be interpreted as a considerable change of the fluid electric properties.

Inter-digital transducers and micro-sensors are usually used for measuring the dielectric constant. Some micro-sensors pose a problem because of the limited depth of dipping due to their relatively small construction, where the individual elements are usually distant between 10 and $50 \mu \mathrm{m}$. Therefore, they can only reach the thin surface layers of the fluid. Besides, they are very sensitive to surface contamination and deposits' formation (Tič and Lovrec, 2017).

Dielectric constant and electric conductivity of mineral based oils are also two temperature-dependent parameters; therefore, calculation must be done related to the reference temperature $\left(40^{\circ} \mathrm{C}\right)$ for easy comparison. The dielectric constants of some frequently used hydraulic fluids and their temperature gradients are shown in Figure 2.

The measurement of the relative permittivity $\varepsilon \mathrm{r}$ is based on a capacitive, oil wetted transducer. The measuring range and resolution can be taken from the general technical specifications. As the relative dielectric constant is dependent

Table 2 Electric conductivity $\sigma$ and dielectric constant $\varepsilon$ r of oil and various contaminants

\begin{tabular}{lll}
\hline Medium & \multicolumn{1}{c}{$\sigma[\mathrm{S} / \mathrm{m}]$} & $\varepsilon_{\mathrm{r}}[-]$ \\
\hline Air & 0.3 to $0.8 \cdot 10^{-14}$ & 1.0006 \\
HM and HLP oils & 3 to $10 \cdot 10^{-10}$ & 2.0 to 2.2 \\
Water & 0.005 to 0.05 & 80 \\
Copper & $5.7 \cdot 10^{7}$ & 6.0 to 6.2 \\
\hline
\end{tabular}


Figure 2 Dielectric constants of various hydraulic fluids and temperature gradients
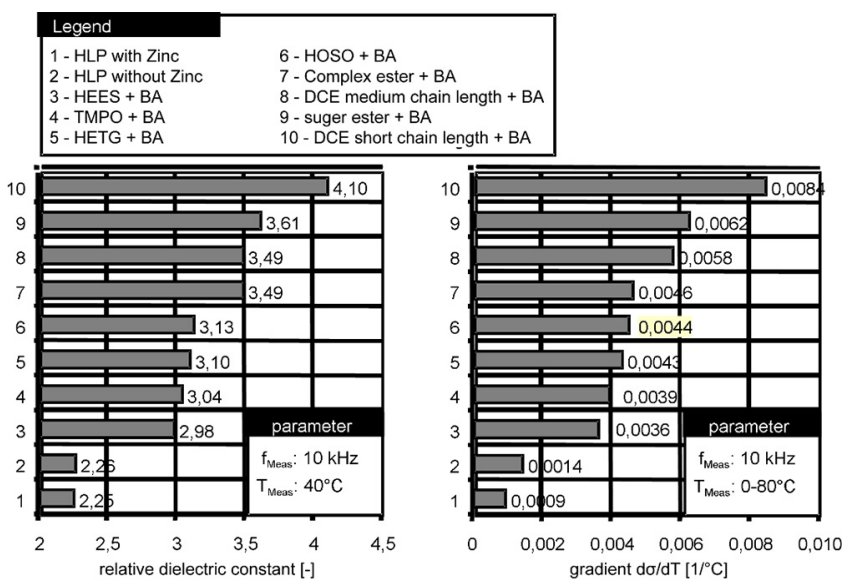

Source: Meindorf (2005)

on the temperature, the sensor performs a conversion to an internal reference temperature of $40^{\circ} \mathrm{C}$ (Tič and Lovrec, 2017; Meindorf, 2005). An additional parameter results from this conversion: The temperature gradient of the characteristic size, which can also be used for the characterisation of the oil. Due to the temperature dependence, the capacitive sensor is usually supplemented by a temperature sensor, so the authors can already talk about a multi-dimensional sensor. Typically, multi-dimensional sensors are supplemented by a sensor for measuring the presence of moisture and/or a sensor for measuring viscosity (depending on the sensor manufacturer).

Measurements of the static dielectric constant of ionic liquids (ILs), to determine how polar they are, are very difficult, because of the decay of the field by the ionic conductivity of ILs. One of the possibilities is the use of dielectric spectroscopy in the megahertz/gigahertz regime to determine the complex dielectric function (Tejwant and Kumar, 2008). According to the literature, results classify ILs as media of moderate polarity. In the cases under test, the dielectric constants fall in the range between $8.8<\varepsilon<15.2$. Dielectric constant $\varepsilon$ decreases with increasing the chain length of the alkyl residue $\mathrm{R}$ of the 1-alyl-3methylamimida-zolium salt. Most reported polarity studies of ILs rely on polarity-sensitive dyes and fluorescence probes. Despite some discrepant results obtained with different probes, some general trends are obvious.

Because the electrical conductivity of ILs prevents measurements of $\varepsilon$ by conventional techniques, many researchers have resorted to indirect methods (Tejwant and Kumar, 2008). Essentially, these alternative methods use nonionic solvents to establish correlations between $\varepsilon_{\mathrm{S}}$ and various spectroscopic, thermodynamic or kinetic polarity probes. As a major result of our study, the dielectric constants of ILs are substantially lower than most estimates from alternative methods. Roughly, we found for some popular ILs $\varepsilon_{\mathrm{S}} \cong 10$. According to the opinion expressed in most papers (Tič and Lovrec, 2017; Meindorf, 2005; Wakai et al., 2005; Tejwant and Kumar, 2008), $\varepsilon_{\mathrm{S}}$ should fall into the range between 20 and 40. Note that, from a practical point of view, the determination of reliable physico-chemical parameters crucially depends on the preparation of samples. With regard to the dielectric constant measurements this point has been addressed carefully in Tič and Lovrec (2017), and it is very unlikely that any contaminations may be responsible for these gross effects (Wakai et al., 2005).

As ionic liquids are a relatively new type of fluid, especially in their practical use as a hydraulic fluid, simply knowing the value of the dielectric constant (for now) is too less for monitoring changes in the state of ILs. In the following, we will, therefore, present, in detail, the usefulness of monitoring the trend of changing the value of the dielectric constant and concluding on the condition and suitability of the use of mineral hydraulic oils, the most common type of hydraulic fluids.

\subsection{On-line measurement of the dielectric constant}

In this study, the dielectric constant of the concerned mineral hydraulic oil was measured by three on-line sensors, while one sensor was available for measuring the electric conductivity. The parameter measuring ranges and the accuracies were given by the manufacturer and are indicated in Table 3.Like for other on-line parameters, for the dielectric constant and electric conductivity the accuracy analysis of our sensors was also performed by the stationary test on the magnetic mixer.

Accurate absolute values of the dielectric constant and electric conductivity for the concerned mineral hydraulic oil were first measured with a precise laboratory device and, in the next step, the on-line sensors were calibrated to the determined values. A summary of results is given in Table 4 .

The results of dielectric constant (DC) measurements by three on-line sensors (S1, S2 and S3) compared to accurate laboratory measurement are shown in Figure 3, indicating that the dielectric constants measured by on-line sensors largely

Table 4 Summary of measurement results of dielectric constant and electric conductivity for sensor $\mathrm{S} 1$

\begin{tabular}{llc}
\hline Temperature $\left[{ }^{\circ} \mathrm{C}\right]$ & $\varepsilon[-]$ & $\sigma[\mathrm{pS} / \mathrm{m}]$ \\
\hline 30 & 2.2636 & 155,6 \\
40 & 2.2492 & 245,7 \\
50 & 2.2403 & 407.3 \\
60 & 2.2314 & 670.6 \\
\hline
\end{tabular}

Table 3 Sensors' measuring ranges and accuracies

\begin{tabular}{lllll}
\hline & \multicolumn{2}{c}{ Dielectric constant $\varepsilon_{\mathrm{r}}$} & \multicolumn{2}{c}{ Electric conductivity $\sigma$} \\
Sensor & Measuring range & Accuracy & Measuring range & Accuracy \\
\hline Sensor S1 & 1 to $7[-]$ & $\pm 0.015[-]$ & 100 to $1000000[\mathrm{pS} / \mathrm{m}]$ & - \\
Sensor S2 & 1 to $5[-]$ & $\pm 0.2[-]$ & - & Typical $<10 \%$ \\
Sensor S3 & 1 to $10[-]$ & not specified & - \\
\hline
\end{tabular}


deviate from the actual dielectric constant of the oil (more details can be found in Tič and Lovrec, 2017).

In the case of physical quantities whose value depends on the temperature, such as, e.g. the viscosity also in the case of the measurement of the dielectric constant it should be calibrated by the first sensor. The calibration curve can be measured for specific types of hydraulic fluids and for each sensor separately. In the case of a new type of hydraulic fluid, the measurements of the accuracy of the dielectric constant should be additionally checked by another laboratory, throughout the measuring range. For economic reasons, only an appropriate conversion of the value to the reference value at $40^{\circ} \mathrm{C}$ is often performed. The absolute value of the dielectric constant is thus unknown. It is also not necessary for on-line monitoring of the condition, as we only follow changes in the dielectric constant and not its absolute value.

Figure 3 also shows that the dielectric constants change linearly with temperature; therefore, their relevant temperature gradient must be found. The linear dielectric constant $g_{\varepsilon}$ gradients for the concerned mineral hydraulic oil and for the individual sensor are indicated in Figure 3 in the form of the linear straight-line coefficient and are equal to:

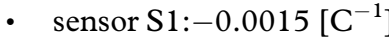

- sensor S2:-0.0065 $\left[\mathrm{C}^{-1}\right]$

- sensor $\mathrm{S} 3:+0.0117\left[\mathrm{C}^{-1}\right]$

The calculation to the reference value of the dielectric constant at $40^{\circ} \mathrm{C} \varepsilon$ (T40) for the individual sensor is done by the use of the measured dielectric constant $g_{\varepsilon}$ temperature gradient, e.g. for sensor S1:

$$
\varepsilon\left(T_{40}\right)=\varepsilon(T)-g_{\varepsilon}(\Delta T)
$$

wherein $\varepsilon\left(T_{40}\right)[-]$ is the dielectric constant at $40^{\circ} \mathrm{C}, \varepsilon(T)[-]$ is the measured dielectric constant at temperature of measurement, $g_{\varepsilon}\left[\mathrm{C}^{-1}\right]$ is the temperature gradient of the dielectric constant, $\Delta T$ $[\mathrm{C}]$ is the difference between the measurement temperature and reference $40^{\circ} \mathrm{C}$.

By calculating the dielectric constant of the measured temperature to the dielectric constant at the reference temperature $40^{\circ} \mathrm{C}$, the trend can be monitored better.

Figure 3 Measurement of dielectric constant by three on-line sensors

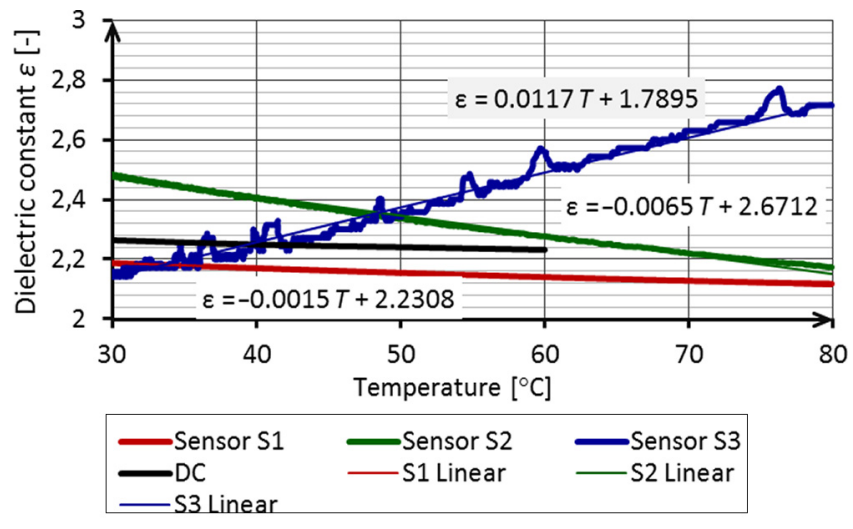

Source: Tič and Lovrec (2017)
An identical procedure as for measuring the dielectric constant was also executed for the electric conductivity measurement, except that it was discovered in this case (Figure 4) that the electric conductivity does not change linearly with the temperature. The relevant equation for the calculation to the electric conductivity reference value at $40^{\circ} \mathrm{C}$ can be found by vertical displacement of the measurement curve (red line) so that it intersects the abscissa at the reference temperature, as shown in Figure 4. It can be observed that the proper quality of the calculation is assured by the third degree polynomial equation.

According to Figure 5, the electric conductivity at the reference temperature $40^{\circ} \mathrm{C} \sigma(T 40)$ will be calculated on the basis of the measured electric conductivity $\sigma(T)$ at the measurement temperature $T$ according to the following equation:

$$
\sigma\left(T_{40}\right)=\sigma(T)-g_{\sigma}(\Delta T)
$$

$$
\begin{aligned}
& \sigma\left(T_{40}\right)=\sigma(T) \\
& \quad-\left(0.0201(\Delta T)^{3}-2.1216(\Delta T)^{2}+97.987(\Delta T)-1811.2\right.
\end{aligned}
$$

Figure 4 Measurement of electric conductivity by on-line sensor

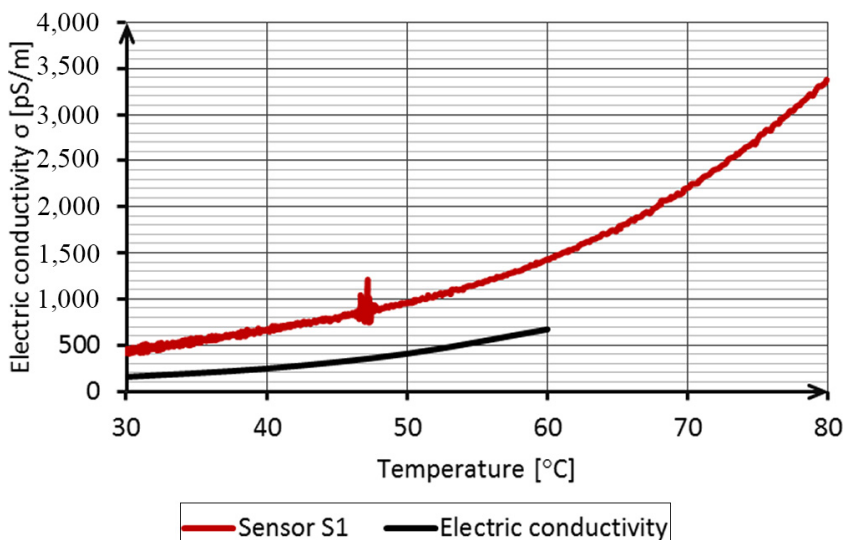

Figure 5 Determination of the equation for calculating the electric conductivity

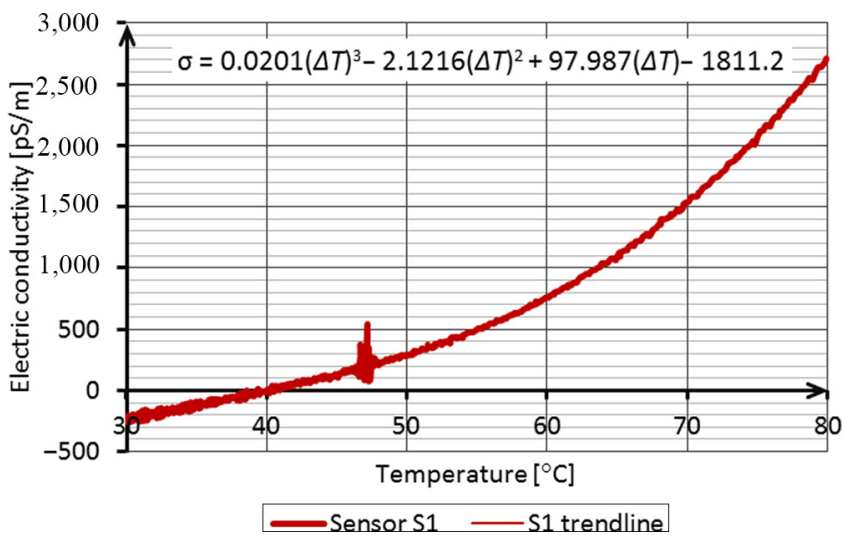


$\sigma\left(T_{40}\right)[\mathrm{pS} / \mathrm{m}]$ is the electric conductivity at $40^{\circ} \mathrm{C}, \sigma(T)[\mathrm{pS} / \mathrm{m}]$ is the electric conductivity at the measurement temperature, $g_{\sigma}[\mathrm{pS} / \mathrm{mC}]$ is the function of the electric conductivity temperature gradient, $\Delta T[\mathrm{C}]$ is the difference between the measurement temperature and reference $40^{\circ} \mathrm{C}$.

\subsection{Dielectric constant of fresh hydraulic fluids with different viscosities}

While monitoring the condition of hydraulic fluid it is necessary to know not only the current hydraulic fluid condition, but also the detailed initial parameters. They are of key importance for all further analyses and for monitoring the trends of individual parameters. Thus, the analysis of various fresh hydraulic fluids was executed, whereas the results will serve as a database for further work and analyses. Analysis of fresh oils was carried out on the following hydraulic fluids:

- HLP ISO VG 46 - mineral hydraulic oil;

- HLP ISO VG 68 - mineral hydraulic oil;

- HLP ISO VG 22 - mineral hydraulic oil;

- DIN 51 517/2: CL ISO VG 220 - high viscosity mineral circulation oil;

- DIN 51 517/2: CL ISO VG 460 - high viscosity mineral circulation oil;

- HFD-U ISO VG68 - fire resistant hydraulic fluid;

- BO 10/95 - base oil; and

- BO N 150 - base oil.

The measurement results obtained by on-line sensors at the reference temperature of $40^{\circ} \mathrm{C}$, are given in Tables 5 and 6 , while the measurement results, as an example for sensors $\mathrm{S} 1$ and S3, show different courses of the dependence of the dielectric constant on temperature, are shown in Figure 6.

The results show that the fresh hydraulic fluid parameters differ considerably, in spite of their related chemical structures.
For example, the concerned HLP type mineral hydraulic oils of different viscosities have a very different dielectric constant and electric conductivity. It can also be indicated that HLP hydraulic oils have a lower dielectric constant and higher electric conductivity, if compared to DIN 51 517/2: CL lubricating oils. In regard to those facts, it is of key importance to know in detail the fresh fluid parameters that will allow high for quality and accurate monitoring of changes in the individual fluids.

Completely different parameters were obtained on HFD-U fire resistant hydraulic fluid. Its initial neutralisation number, as well as its dielectric constants and electric conductivity, are rather high in comparison to common mineral oils.

An opposite phenomenon can be observed for the base oils, as their neutralisation number, as well as their dielectric constant and electric conductivity, are very low. It can be concluded that the additive packets added to the base oil increase the mentioned parameters.

The calibration viscosity curves for both used sensors were determined for all tested hydraulic fluids to improve the accuracy of these measurements. The relevant temperature gradients of the dielectric constants and electric conductivity were determined for each tested hydraulic fluid, to allow calculation of the mentioned parameters to the reference value at $40^{\circ} \mathrm{C}$. The results concerned are indicated in Table 6 as functions of calibration curves.

\section{Conclusions}

Knowledge of the electrical quantities of built-in hydraulic fluid is very useful when making strategic decisions about the design of a hydraulic power unit, or knowing the physico-chemical condition of the used fluid.

Table 5 Dielectric constant and electric conductivity of different fresh hydraulic fluids

\begin{tabular}{llcccccccc}
\hline Sample & Unit & VG 46 & HLP & HG 68 & VG 22 & $\begin{array}{c}\text { DIN 51 517/2 } \\
\text { CL VG 220 }\end{array}$ & $\begin{array}{c}\text { DIN 51 517/2 } \\
\text { CL VG 460 }\end{array}$ & $\begin{array}{c}\text { HFD-U } \\
\text { VG 68 }\end{array}$ & $\begin{array}{c}\text { BO } \\
10 / 95\end{array}$ \\
\hline Dielectric constant S1 & {$[-]$} & 2.1701 & 2.1644 & 2.1510 & 2.2429 & 2.2747 & 3.1013 & 2.1391 \\
Dielectric constant S2 & {$[-]$} & 2.4050 & 2.3960 & 2.3330 & 2.5020 & 2.5430 & 3.3470 & 2.3360 \\
Dielectric constant S3 & {$[-]$} & 2.2859 & 2.2286 & 2.1999 & 2.2715 & 2.2859 & 3.3740 & 2.1713 & 2.0568 \\
Electric conductivity S1 & {$[\mathrm{pS} / \mathrm{m}]$} & 668 & 450 & 1001 & 358 & 309 & 2689 & 234 \\
\hline
\end{tabular}

Table 6 Functions of calibration curves for mineral based oils and HFD-U fluid

\begin{tabular}{llll}
\hline Parameter & \multicolumn{1}{c}{ HLP VG 22 } & \multicolumn{1}{c}{ HLP VG 46 } & \multicolumn{1}{c}{ HLP VG 68 } \\
\hline DC S1 & $-0.0014(\Delta T)$ & $-0.0015(\Delta T)$ & $-0.0015(\Delta T)$ \\
DC S2 & $-0.0064(\Delta T)$ & $-0.0065(\Delta T)$ & $-0.007(\Delta T)$ \\
DC S3 & $0.0090(\Delta T)$ & $0.0117(\Delta T)$ & $0.0099(\Delta T)$ \\
EC S1 & $0.0259(\Delta T)^{3}-2.7087(\Delta T)^{2}+$ & $0.02(\Delta T)^{3}-2.1121(\Delta T)^{2}+$ & $0.0139(\Delta T)^{3}-1.7236(\Delta T)^{2}+$ \\
& $132.76(\Delta T)-2633.2$ & $97.481(\Delta T)-1802.7$ & $82.021(\Delta T)-1413.6$ \\
& DIN 51 517/2: CL VG 220 & DIN 51 517/2: CL VG 460 & HFD-U VG 68 \\
DC S1 & $-0.0018(\Delta T)$ & $-0.0019(\Delta T)$ & $-0.0041(\Delta T)$ \\
DC S2 & $-0.0076(\Delta T)$ & $-0.0079(\Delta T)$ & $-0.0080(\Delta T)$ \\
DC S3 & $0.0089(\Delta T)$ & $0.0045(\Delta T)$ & $0.0045(\Delta T)$ \\
EC S1 & $0.0052(\Delta T)^{3}-0.6992(\Delta T)^{2}+$ & $0.0066(\Delta T)^{3}-0.9462(\Delta T)^{2}+$ & $0.0241(\Delta T)^{3}-0.7824(\Delta T)^{2}+$ \\
& $38.505(\Delta T)-765.21$ & $48.868(\Delta T)-862.52$ & $70.289(\Delta T)-3096.4$ \\
\hline
\end{tabular}


Figure 6 Dielectric constant of on-line sensors S1 and S3 throughout the temperature range for tested fluids
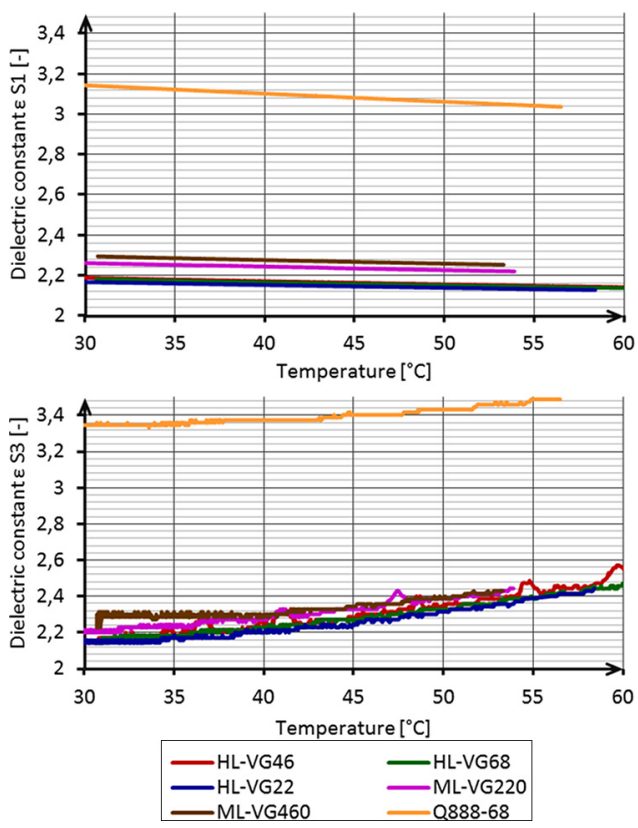

The electrical insulating capabilities of the fluid given by the breakdown voltage help in the decision making regarding the design of the hydraulic drive unit. Although there are no problems with conventional mineral oils due to their good insulating properties, it is necessary to pay special attention to this property with other types of hydraulic fluids.

Knowledge of the value the dielectric constant and electrical conductivity for different types of hydraulic fluids and the known mechanism of changing values, depending on different operating parameters, are the necessary basis for recognising the current condition of hydraulic fluid, as well as designing a system for predicting the remaining useful life. In the case of tracking the change of the dielectric constant with precalibrated on-line sensors, it provides insight into the change of the value of the dielectric constant over time. This can be obtained on the basis of previous tests, based on various accelerated mechanical, as well as thermal tests for accelerated fluid loading under stringent test conditions.

Based on the known initial value of the dielectric constant and its changes obtained on the basis of the mentioned tests, we can design a method for evaluating oil condition and predicting remaining useful lifetime. Based only on dielectric constant value changes, or supplemented by other quantities treated in a similar way, we have at our disposal a very powerful tool for strategic, on-line assessment of the condition and usability of hydraulic fluid.

\section{References}

Carey, A.A. and Hayzen, A.J. (2001), "Dielectric constant and oil analysis", available at; www.machinerylubrication.com/ Articles/Print/226 (accessed 30 April 2021).

Gunderson, S., Fultz, G., Snyder, C.E., Wright, J., Gschwender, L. and Heidger, S. (2011), "The effect of water content on the dielectric strength of polyalphaolefin (PAO) coolants", IEEE Transactions on Dielectrics and Electrical Insulation, Vol. 18 No. 1, pp. 295-302.

IEC 60156 (2018), "Insulating liquids - determination of the breakdown voltage at power frequency - test method", Edition 3.0

IEC 60296 (2020), "Fluids for electrotechnical applications mineral insulating oils for electrical equipment", Edition5.02020-06.

Meindorf, T. (2005), Sensoren Für Die OnlineZustandsüberwachung Von Druckmedien Und Strategien Zur Signalauswertung, Shaker Verlag, Aachen.

Tejwant, S. and Kumar, A. (2008), "Static dielectric constant of room temperature ionic liquids: internal pressure and cohesive energy density approach", The Fournal of Physical Chemistry B, Vol. 112 No. 41, pp. 12968-12972, doi: $10.1021 /$ jp8059618.

Tič, V. and Lovrec, D. (2017), On-Line Condition Monitoring and Evaluation of Remaining Useful Lifetimes for Mineral Hydraulic and Turbine Oils, 1st ed., University of Maribor Press, Maribor, doi: 10.18690/978-961-286-130-8, available at: http://press.um.si/index.php/ump/catalog/book/309

Tič, V., Tašner, T. and Lovrec, D. (2014), "Enhanced lubricant management to reduce costs and minimise environmental impact”, Energy, Vol. 77, pp. 108-116.

Wakai, C., Oleinikova, A., Ott, M. and Weingaertner, H. (2005), "How polar are ionic liquids? Determination of the static dielectric constant of an imidazolium-based ionic liquid by microwave dielectric spectroscopy", f Phys Chem B, Vol. 109 No. 36, pp. 17028-17030, doi: 10.1021/jp053946.

\section{Corresponding author}

Vito Tič can be contacted at: vito.tic@um.si 